\title{
PERSONAL DE VUELO DE LAS COMPAÑÍAS AÉREAS: TRIBUNAL INTERNACIONALMENTE COMPETENTE EN MATERIA DE CONTRATO INDIVIDUAL DE TRABAJO. (ALGUNAS REFLEXIONES EN TORNO A LA STJUE 14 SEPTIEMBRE 2017 ASUNTOS ACUMULADOS CREWLINK Y RYANAIR
}

\author{
JURISDICTION OVER INDIVIDUAL CONTRACTS OF \\ EMPLOYMENT. (SOME REFLECTIONS ON THE JUDGMENT \\ OF THE ECJ SEPTEMBER 14, 2017, IN JOINED CASES \\ CREWLINK AND RYANAIR)
}

\author{
Aurora Hernández Rodríguez \\ Profesora Contratada Doctora de Derecho Internacional Privado \\ Universidad de Cantabria
}

Recibido: 26.07.2018 / Aceptado: 06.09.2018

DOI: https://doi.org/10.20318/cdt.2018.4407

\begin{abstract}
Resumen: La relación jurídico-laboral del personal de vuelo reviste cierta complejidad, especialmente, por las circunstancias en las que se desarrolla. A diferencia de lo que sucede en otras relaciones laborales típicas, en la actividad aérea no existe un lugar de trabajo fijo, estable y duradero. El TJUE, en su Sentencia 14 septiembre 2017, Asuntos acumulados Crewlink y Ryanair, se pronuncia por primera vez sobre la interpretación del art. 19.2 a) Reglamento Bruselas-I a efectos de determinar cuál es el "lugar donde desempeña habitualmente su trabajo" el personal de vuelo. Para ello, y tomando como referencia la jurisprudencia ya existente en torno a la mencionada disposición, el Tribunal de Justicia soluciona la cuestión creando una presunción que conduce a equiparar dicho lugar con la "base" asignada por el operador a cada uno de los trabajadores. Dicha solución que podría considerarse satisfactoria, en tanto que aporta previsibilidad y seguridad jurídica, deja de serlo desde el momento en que el propio TJUE admite la posibilidad de que la presunción se enerve recurriendo de forma "insólita a la "cláusula de excepción", mecanismo técnico jurídico reservado al conflicto de leyes, y dejando la puerta abierta con ello al forum non conveniens en materia de contratos individuales de trabajo.

Palabras clave: contratos individuales de trabajo, personal de vuelo, trabajo a bordo de aeronaves, competencia judicial internacional, lugar donde el trabajador desempeña habitualmente el trabajo, Reglamento Bruselas-I, forum non conveniens, cláusula de excepción.
\end{abstract}

\footnotetext{
Abstract: The legal-labor relationship of flight personnel is somewhat complex, especially due to the circumstances in which it is carried out. Unlike what happens in other typical work relationships, in the aerial activity there is no fixed, stable and lasting workplace. The CJEU, in its Judgment 14 September 2017, Cumulative Matters Crewlink and Ryanair, pronounces for the first time on the interpretation of art. 19.2 a) Brussels-I Regulation in order to determine the "place where flight personnel habitually carried out its work". For this, and taking as reference the existing jurisprudence around the aforementioned provision, the Court of Justice solves the issue by creating a presumption that leads to equating that place with the "base" assigned by the operator to each of the workers. This solution, which could be considered satisfactory, in so far as it provides predictability and legal certainty, ceases to be so from the
} 
moment the CJEU itself admits the possibility that the presumption may be relied upon by the "unusual" resort to the "exception clause", mechanism reserved to the conflict of laws, leaving the door open with it to forum non conveniens in matter of individual contracts of employment.

Keywords: individual contracts of employment, flight personnel, personnel working on board aircraft, jurisdiction, place where the employee habitually carries out his work, Brussels I Regulation, forum non conveniens, exception clause.

Sumario: I. Introducción. II. STJUE (Sala Segunda), 14 septiembre 2017, Asuntos acumulados Crewlink y Ryanair. 1. Hechos. A) Asunto C-168/16. B) Asunto C-169/16. 2. Cuestión prejudicial judicial planteada ante el TJUE. III. Protección del trabajador y competencia judicial internacional. A) Litigios laborales y sumisión de las partes. B) trabajador demandante: locus labori. IV. Lugar donde desempeña habitualmente su trabajo el personal de vuelo: el concepto de "base" como presunción. 1. Interpretación autónoma. 2. Interpretación amplia. 3. Método analítico: el concepto de "base" como presunción". V. Algunas consideraciones críticas. 1. Un error de base. 2. ¿Hacia una admisión del forum non conveniens en materia de contratos individuales de trabajo?. 3. La "desnaturalización" de la "cláusula de excepción". 4. Desenlace. VI. Conclusiones.

\section{Introducción}

1. Más tarde que pronto, la cuestión de la determinación del "lugar donde presta habitualmente su trabajo" la tripulación de las compañías aéreas (flight personnel), a efectos de fijar la competencia judicial internacional de los tribunales nacionales de los Estados miembros de la UE en materia de contratos individuales de trabajo, tenía que llegar ante el TJUE¹. Y así ha sido. En su Sentencia de 14 de septiembre de 2017, el alto Tribunal ha tenido que pronunciarse al respecto, realizando importantes aportaciones que, sin embargo, y desde el punto de vista de la técnica jurídica, invitan a cierta reflexión crítica².

2. La problemática no resulta novedosa para los tribunales de los social de los Estados miembros de la UE que, de un tiempo a esta parte, vienen haciendo frente a lo que podríamos denominar litigio "tipo" cuyo objeto suele ser un despido improcedente o la reclamación de ciertas prestaciones, tras la

1 No es la primera vez, sin embargo, que se plantea esta cuestión ante el TJUE. Vid. Auto TJCE 10 junio 2004, Asunto C-555/03, Magali Warbecq c. Ryanair Ltd. Si bien, en esa ocasión, el Tribunal de Justicia no pudo entrar a resolver las cuestiones prejudiciales planteadas por el órgano remitente por carecer éste último, según el ex art. 234 TCE (actual art. 267 TFUE), de competencia para plantear las mismas, en tanto que, por aquél entonces, solo se atribuía tal facultad a los órganos jurisdiccionales de los Estados miembros cuyas resoluciones no admitieran ulterior recurso. Los hechos que dieron lugar a esta consulta fueron los siguientes: La Sra. Warbecq fue contratada por Ryanair, mediante contrato de trabajo suscrito en Dublín, el 19 de abril de 2004, en calidad de "customer service agent-inflight". El 10 de abril de 2002, Ryanair extinguió el contrato y pagó a la Sra. Warbecq una indemnización. Con posterioridad, la Sra. Warbecq demandó a Ryanair ante el Tribunal Laboral de Charleroi (Bélgica), solicitando el pago de ciertas cantidades en concepto de indemnización. Según la demandante, en aplicación del art. 19 Reglamento Bruselas-I, podía demandar al empresario, a su elección, ante los tribunales del domicilio de éste, o ante los tribunales del lugar en el que se desempeñaba habitualmente el trabajo, según ella y en este caso, el aeropuerto de Charleroi. Por su parte, Ryanair sostenía que los tribunales belgas carecían de competencia judicial internacional para entrar a conocer de este asunto. En este caso, el Tribunal Laboral de Charleroi (Bélgica) decidió suspender el procedimiento y plantear las siguientes cuestiones prejudiciales ante TJCE: $1^{\text {a }}$ ) Cuáles eran los criterios que permitían determinar el Estado miembro en cuyo territorio un trabajador desempeña habitualmente su trabajo, en los casos en los que un trabajador está contratado como miembro del personal de vuelo de una compañía que realiza el transporte internacional de pasajeros por vía aérea, a efectos del art. 19. 2 a) del Reglamento (CE) 44/2001 del Consejo, de 22 de diciembre de 2000; 2a) Qué lugar debía ser considerado como el lugar en el cual o desde el cual el trabajador cumplía de hecho lo esencial de sus obligaciones respecto a su empresa, cuando las obligaciones nacidas de ese contrato de trabajo se ejecutan en parte en tierra (aeropuerto) de un Estado miembro, y en parte a bordo de una aeronave, cuya nacionalidad es la de otro Estado miembro, en el que además fue contratado ese trabajador.

Lamentablemente, y por una cuestión de competencia, como ya se ha señalado, el TJCE no pudo entrar a resolver las cuestiones planteadas.

2 STJUE 14 septiembre 2017, Asuntos acumulados C-168/16 y C-169/16, Nogueira y otros c. Crewlink Ireland Ltd, y Moreno Osácar c. Ryanair, (en adelante, Asuntos Crewlink y Ryanair) con comentarios de: N. NIHMAn, "Personnel navigant et compétence internationale: commentaire de l'ârret de la CJUE du 14 septembre 2017", Revue de Droit du Travail, 2017, pp. 816-821; L. PAILER, "Nota", JDI, 2018, 2, pp. 585-601. 
resolución de un contrato de trabajo, por parte del personal de vuelo contra una compañía aérea, en la mayoría de los casos por no decir todos, la compañía Ryanair y/o las ETT que prestan sus servicios de cesión de personal a la primera, Crewlink y/o Work Force. Todas estas compañías tienen su sede en Irlan$\mathrm{da}$, los contratos que celebran normalmente en aquel país con el personal de vuelo responde a un modelo redactado en inglés, en el que con alguna que otra variación, se especifican las prestaciones del personal de la tripulación (tareas de embarque, desembarque, seguridad, servicio de venta a bordo y limpieza de la aeronave, etc...), se les asigna a cada uno de ellos una "base", -lugar en el que reciben la organización de la jornada diaria de vuelo, siendo este el lugar de donde parten y al que regresan tras finalizar la misma y donde se les obliga a fijar su residencia a menos de una hora-, y a percibir su salario a través de una cuenta abierta en una entidad bancaria irlandesa a tal efecto. En este tipo de contratos, se incluyen siempre dos cláusulas de especial importancia desde el punto de vista del DIPr: una cláusula de atribución de competencia judicial internacional a los tribunales irlandeses para conocer de todo litigio que se puede derivar del contrato de trabajo, y una cláusula de elección de la ley irlandesa, como lex contractus.

3. Surgido el litigio, el trabajador demandante suele acudir en la mayoría de los casos ante los tribunales más cercanos, esto es, los tribunales del país donde se encuentra la "base" y, que en la mayoría de las ocasiones coincide con el lugar de su residencia habitual. Es entonces, cuando la compañía aéreademandada impugna la competencia judicial internacional alegando la existencia de una cláusula de elección de foro a favor de los tribunales irlandeses inserta en el contrato, junto con la nacionalidad irlandesa de la aeronave lugar dónde, según el empresario, desempeña habitualmente su trabajo la tripulación ${ }^{3}$.

\section{STJUE (Sala Segunda), de 14 de septiembre de 2017, Asuntos Crewlink y Ryanair}

\section{Hechos}

4. En un contexto similar al que se acaba de exponer más arriba, se plantea la STJUE de 14 de septiembre 2017, en los Asuntos acumulados C-168/16 y C-169/16, que inmediatamente pasamos a exponer.

\section{A) Asunto C-168/16}

5. Durante 2009 y 2010, Sandra Nogueira, Víctor Pérez Ortega, Virginie Mauguit, María Sánchez O'Dogherty y José Sánchez Navarro, de nacionalidad portuguesa, española y belga, celebraron sendos contratos de trabajo con Crewlink, persona jurídica domiciliada en Irlanda.

6. Cada uno de los contratos de trabajo establecía que los trabajadores serían empleados por Crewlink y puestos a disposición de Ryanair como personal de cabina. Los contratos de trabajo estaban redactados en inglés y establecían que las relaciones laborales respectivas quedaban sujetas al Derecho irlandés y que los tribunales de ese Estado miembro eran los competentes para conocer de todos los litigios relativos al cumplimiento y a la denuncia de tales contratos y que el Derecho irlandés sería el aplicable. Los contratos estipulaban que el pago de la remuneración se produciría en una cuenta bancaria irlandesa, que los aviones del cliente estaban matriculados en Irlanda y, dado que las tareas se ejercerían en esas aeronaves, el puesto de trabajo estaba situado en Irlanda, y que el aeropuerto de Charleroi (Bélgica) sería la "base" de esos trabajadores y que todos ellos debían residir a una hora de distancia de la misma.

\footnotetext{
${ }^{3}$ En España, al igual que en otros Estados miembros de la UE donde opera la compañía aérea Ryanair, existe una abundante jurisprudencia al respecto. Baste citar como ejemplo: TJ (Sala de lo Social, Sección 1a), Auto 2 julio 2015, JUR 2015\196183; TS (Sala de lo Social), Sentencia 30 diciembre 2013, RJ $2013 \backslash 8369$; JS Barcelona, Sentencia 22 septiembre 2017, AS $\backslash \mid 2017 \backslash 1977$; TSJ Cataluña (Sala de lo Social, Sección 1'), Sentencia núm. 4166/2015 de 25 junio, AS 2016\365; TSJ Cataluña, (sala de lo Social, Sección 1a), Sentencia núm. 166/2014 de 14 de enero, JUR\2014\47370; TSJ C. Valenciana, (Sala de lo Social, Sección $1^{\mathrm{a}}$ ), Sentencia núm. 196/2017 de 26 de enero, JUR\2017\114077; TSJ C. Valenciana, /Sala de lo Social, Sección 1ª), Sentencia núm.2200/2012 de 11 septiembre, JUR\2012\360860.
} 
7. El personal de vuelo comenzaba su jornada de trabajo en el aeropuerto de Charleroi y volvía sistemáticamente a la "base" al final de cada jornada. De igual forma, todos los trabajadores y trabajadoras se habían visto obligados en algún momento a hacer guardias en el aeropuerto de Charleroi por si era necesario sustituir a algún empleado que no hubiera acudido al trabajo. Por otro lado, la existencia de un local común de Ryanair y Crewlink en el aeropuerto de Charleroi y el ejercicio de potestades disciplinarias por parte de la dirección de Ryanair sobre el personal puesto a su disposición por Crewlink, probaba la existencia de una comunidad de trabajo entre el personal de ambas empresas.

8. Las relaciones laborales cesaron durante 2011, en unos casos por despido y en otros por voluntad de los trabajadores. Fue entonces cuando la Sra. Nogueira y otros interpusieron unas demandas ante el Tribunal Laboral de Charleroi para lograr el abono de diversas indemnizaciones.

9. Mediante resolución de 4 de noviembre de 2013, dicho órgano jurisdiccional consideró que los tribunales belgas no eran competentes para conocer del asunto. Contra dicha resolución, los demandantes en el litigio principal apelaron ante el Tribunal Laboral Superior de Mons (Bélgica).

\section{B) Asunto C-169/16}

10. El 21 de abril de 2008, el Sr. Moreno Osácar celebró en España un contrato de trabajo con Ryanair, cuyo domicilio social se encentra en Irlanda. En virtud de dicho contrato, sus funciones incluían "la seguridad y el control de los pasajeros y la atención y asistencia a éstos; las tareas de embarque y en tierra (...), la venta a bordo del avión; la limpieza del interior del avión, las comprobaciones de seguridad y todas las tareas pertinentes que pueda (...) encomendarle la empresa".

11. En dicho contrato, que estaba redacto en inglés, se indicaba que los tribunales competentes para conocer de los litigios que pudieran surgir entre las partes en relación con el cumplimiento y la denuncia del propio contrato eran los tribunales irlandeses, y la relación laboral entre ambas partes se regiría por la legislación de ese mismo Estado. El contrato indicaba asimismo que las prestaciones laborales como personal de cabina se consideraban realizadas en Irlanda, ya que ejercía sus funciones a bordo de aviones matriculados en ese Estado miembro y propiedad de esa compañía aérea. Por otro lado, se le asignaba como "base" el aeropuerto Charleroi (Bélgica) y se le obligaba a vivir a una hora de distancia de esa "base".

12. El 16 de junio de 2011, el Sr. Moreno Osácar dejó su puesto. Unos meses después, concretamente el 8 de diciembre de 2011, interpuso demanda ante el Tribunal Laboral de Charleroi contra Ryanair solicitando se le abonaran diversas indemnizaciones en aplicación de la normativa belga. La empresa demandada impugnó la competencia de los tribunales belgas en base a los siguientes argumentos: 1) la existencia de una cláusula de sumisión expresa a los tribunales irlandeses así como una cláusula que designación del Derecho irlandés, como ordenamiento jurídico rector del contrato; 2) la aplicación de la normativa irlandesa en materia tributaria y de seguridad social en tanto que el contrato de trabajo se había cumplido a bordo de aviones matriculados en Irlanda y con arreglo a la normativa de ese mismo Estado miembro y; 3) el lugar de perfeccionamiento del contrato, según la compañía aérea, era Irlanda.

13. Por resolución de 4 de noviembre de 2013, el Tribunal Laboral de Charleroi declinó la competencia de los tribunales belgas para conocer de esta demanda. Resolución que fue impugnada ante el Tribunal Laboral Superior de Mons (Bélgica).

\section{Cuestión prejudicial planteada ante el TJUE}

14. En ambos supuestos, el tribunal belga decidió suspender el procedimiento y plantear ante el TJUE sendas cuestiones prejudiciales en términos muy similares. En definitiva, se trataba de dilucidar si en caso de acciones ejercitadas por trabajadores miembros del personal de vuelo propio de una com- 
pañía aérea o puesto a su disposición, y a fin de determinar la competencia del tribunal al que se haya sometido el asunto, el concepto de "lugar en el que el trabajador desempeñare habitualmente su trabajo", en el sentido del artículo 19. 2 a) del Reglamento (CE) núm. 44/2001 del Consejo, de 22 de diciembre de 2000, relativo a la competencia judicial, el reconocimiento y la ejecución de resoluciones en materia civil y mercantil (en adelante, Reglamento Bruselas I), es asimilable al concepto de "base", tal y como aparece regulado en determinadas normas de derecho derivado europeo.

15. Concretamente, el órgano remitente se refiere al Reglamento (CEE) núm. 3922/91 del Consejo, de 16 de diciembre de 1991, relativo a la armonización de normas técnicas y procedimientos administrativos aplicables a la aviación civil ${ }^{5}$. Dicho Reglamento: a) establece la obligación del operador de asignar una "base" a cada miembro de la tribulación (anexo III, sub-parte Q, OPS 1.1090); b) define el concepto de "base" como el "lugar asignado por el operador a cada tripulante, en el cual habitualmente éste comienza y termina un período de actividad o una serie de períodos de actividad y en el que, en condiciones normales, el operador no se responsabiliza del alojamiento del tripulante" (anexo III, sub-parte Q, OPS 1.1095); y c) regula el tiempo de descanso mínimo de los miembros de la tripulación según el comienzo de la actividad de vuelo tenga su inicio en la base o fuera de la misma (anexo III, sub-parte Q, OPS 1.1110).

También se refiere expresamente al concepto de "base", en términos similares, el Reglamento (CE) núm. 883/2004 de 29 de abril de 2004, del Parlamento europeo y del Consejo, sobre la coordinación de los sistemas de seguridad social (considerando 18 ter, art. 11.5) ${ }^{6}$.

16. En definitiva, se trata de dilucidar si el concepto de "base" proporcionado por el Derecho europeo de navegación aérea puede servir como criterio para determinar la competencia judicial internacional, -a efectos del art. 19.2 a) Reglamento Bruselas-I-, entendido como "centro efectivo de la relación laboral" en la medida en que el trabajador comienza en ella su jornada de trabajo y la termina en ese lugar, organizando en ella su trabajo cotidiano, y cerca del cual ha establecido su residencia efectiva durante el período de las relaciones contractuales. Si así fuese, el hecho de que el personal de vuelo prestase, gran parte de sus servicios a bordo de una aeronave pasaría a un segundo plano a efectos de determinación de la competencia judicial internacional.

\footnotetext{
${ }^{4}$ DO L núm. 012, de 16 de enero de 2001. Dicho Reglamento ha sido reemplazado por el Reglamento (UE) núm. 1215/2012, del Parlamento Europeo, de 12 de diciembre, relativo a la competencia judicial, el reconocimiento y la ejecución de resoluciones judiciales en material civil y mercantil, (en adelante, Reglamento Bruselas I-bis), DO L núm. 351, de 20 de diciembre de 2012.

${ }^{5}$ DO L núm. , de 31 de diciembre de 1991, p. 4, en la redacción dada por el Reglamento (CE) núm. 1899/2006 del Parlamento Europeo y del Consejo, de 12 de diciembre de 2006 (DO L núm. 377, de 27 de diciembre de 2006, p. 1). El Reglamento (CE) núm. 3922/91 ha sido derogado por el Reglamento (CE) núm. 216/2008 del Parlamento Europeo y del Consejo, de 20 de febrero de 2008, sobre normas comunes en el ámbito de la aviación civil y por el que se crea una agencia europea de seguridad aérea, y se deroga la Directiva 91/670/CEE del Consejo, el Reglamento (CE) núm. 1592/2002 y la Directiva 2004/36/CE (DO L núm. 79, de 8 de junio de 2012, p.1).

${ }^{6}$ DO L núm. 166, de 30 de abril de 2004, p. 1, en su redacción dada por el Reglamento (UE) núm. 465/2012 del Parlamento Europeo y del Consejo, de 22 de mayo de 2012, DO L núm. 149, de 8 de junio de 2012, p. 4.

En materia de seguridad social, según el Considerando 18 ter del Reglamento (CE) núm. 883/2004: "En el anexo III del Reglamento núm. 3922/91 se define el concepto de "base" para los miembros de tripulaciones de vuelo y de cabina como el "lugar asignado por el operador a cada tripulante, en el cual habitualmente éste comienza y termina uno o varios período de actividad y en el que, en condiciones normales, el operador no se responsabiliza del alojamiento del tripulante". Con el fin de facilitar la aplicación del título II del presente Reglamento a los miembros de tripulaciones de vuelo y e cabina, está justificado tomar este concepto de "base" como criterio para determinar cuál es la legislación aplicable a los miembros de las tripulaciones de vuelo y de cabina. Sin embargo, la legislación aplicable a los miembros de las tripulaciones de vuelo y de cabina debe mantenerse estable y el principio de "base" no ha de entrañar cambios frecuentes de legislación aplicable debido a los modelos de trabajo del sector industrial o a demandas estacionales".

También conviene resaltar, tal y como establece el art. 11. 5 Reglamento (CE) núm. 883/2004, que: "la actividad de un miembro de tripulación de vuelo o de cabina en el marco de una prestación de servicios de transporte aéreo de pasajeros o mercancías, se considerará una actividad realizada en el Estado miembro en el que se encuentre la "base" con arreglo a la definición que figura en el anexo III del Reglamento (CEEE) núm. 3922/91". No obstante, esta última disposición no puede ser tenida en cuenta en el asunto del que trae causa la sentencia que aquí comentamos, por no estar en vigor cuando se plantea la demanda (vid. art. 3 Reglamento núm. 465/2012, según el cual el art 11. 5 del Reglamento núm 883/2004, entrará en vigor a los veinte días de su publicación en el Diario Oficial, esto es, el 8 de junio de 2012).
} 


\section{Protección al trabajador y competencia judicial internacional}

17. A modo introductorio, conviene recordar que la protección a la parte débil del contrato, en este caso el trabajador, se ha venido modulando tradicionalmente en sede de competencia judicial internacional mediante la articulación de reglas más favorables a los intereses de esa parte 7 . De un lado, se ponen a su disposición diversos foros para accionar contra el empresario, mientras que éste al contrario, solo puede demandar ante el tribunal del domicilio del trabajador. Con ello se trata de facilitar el acceso a la justicia del contratante más débil al tribunal que le sea más favorable. De otro lado, los pactos atributivos de competencia se someten a un régimen más restrictivo que el general para evitar que la posición desigual de los contratantes lleve al más fuerte a imponer a su contraparte una elección del tribunal que le sea desfavorable, frustrando así los objetivos de protección perseguidos ${ }^{8}$.

18. Así queda modulado el sistema de protección previsto por el Reglamento de Bruselas-I, que destina la Sección 5a del Capítulo II (arts. 18-21 Reglamento Bruselas-I) a regular con carácter exclusivo

\footnotetext{
${ }^{7}$ No obstante, el Convenio de Bruselas de 27 de septiembre de 1968 (en adelante, $\mathrm{CBr}$ ) en su versión originaria no dedicó atención alguna al contrato individual de trabajo, sometiendo su tratamiento al sistema general de contratos. De esta manera, la competencia judicial internacional quedaba regulada por los foros del art. $17 \mathrm{CBr}$, art. $5.1 \mathrm{CBr}$ y art. $2 \mathrm{CBr}$. Situación ésta que contrastaba con el régimen espacial previsto para proteger a la parte más débil en los casos del asegurado (arts. 7 a $12 \mathrm{CBr}$ ) y el consumidor (arts. 13 a $15 \mathrm{CBr}$ ). Ello se traducía en una negación al reconocimiento del estatuto de la parte débil en materia de contratos de trabajo, al contrario de lo que sucedía en la mayor parte de los ordenamientos estatales El anteproyecto del $\mathrm{CBr}$ previa la inclusión de foros especiales en esta materia, si bien fueron finalmente excluidos del texto definitivo, por hallarse entonces en curso diversos trabajos de armonización del Derecho laboral en el seno de la Comunidad. La ausencia de mención explícita alguna a los contratos de trabajo, generó incluso dudas sobre la posible aplicación del $\mathrm{CBr}$ a los mismos, en tanto que en algunos Estados la contratación laboral se sometía a intervenciones legales tan intensas que hacían dudar de su carácter privado. Mientras que en algunos sistemas jurídicos la autonomía de la voluntad jugaba un papel importante en la formación y desarrollo del contrato, en otros el papel protagonista lo jugaba la ley, acercando la relación laboral a una contratación reglada, próxima a la contratación administrativa, y en todo caso alejada de la materia "civil y mercantil" objeto de regulación del CBr. De todos modos, el TJCE zanjó pronto este debate advirtiendo que los contratos de trabajo también quedaban incluidos en su ámbito material aplicación (STJCE 13 noviembre 1979, Asunto C-25/79, Sanicentral). Vid. M. CASAdo abarquero, La autonomía de la voluntad en el contrato de trabajo internacional, Cizur Menor, Thomson Aranzadi, 2008, pp. 134-135; P. JUÁREZ PÉREZ, Orden Social y litigios internacionales: competencia judicial, Granada, Comares, 2002, p. 100.

${ }^{8}$ Tras la entrada en vigor del $\mathrm{CBr}$, y ante la ausencia de foros de protección en esta materia, la realidad contractual laboral comenzó a proporcionar datos alarmantes sobre el uso abusivo de los acuerdos atributivos de competencia judicial por parte de los empresarios. Situación ésta que compelía a los trabajadores, una vez surgido el litigio, a renunciar a la tutela judicial efectiva, por verse obligados a acudir ante los tribunales de un Estado muy alejado de su domicilio y muy próximo al empleador. Pero los acuerdos de elección de foro no eran el único problema, también perjudicaba gravemente a la parte débil del contrato de trabajo el foro en material contractual previsto en el art. 5.1 CBr para todo tipo de contratos y que atribuía competencia judicial a los tribunales del lugar de cumplimiento de la obligación que sirve de base a la demanda. El método analítico-distributivo establecido por el propio TJCE para determinar este foro en materia contractual y el hecho de que en la mayoría de los litigios laborales el demandante fuera el trabajador, le obligaba de nuevo a desplazarse lejos del lugar de su domicilio o incluso del lugar dónde había prestado sus servicios, y desplazarse hacia el lugar donde hubiese incumplido el empresario la obligación que servía de base a la demanda. El propio TJCE vino a cambiar pronto dicha situación consagrando una regla especial propia para el contrato individual de trabajo inspirándose en las soluciones existentes para los contratos de seguro y de consumo, y en la línea que se había impuesto en el ámbito del conflicto de leyes, en el Convenio de Roma, de 19 de junio de 1980, sobre ley aplicable a obligaciones contractuales (art. 6.2 CR). De tal forma, el TJCE estableció que en relación a los contratos individuales de trabajo, el lugar relevante para determinar la competencia judicial internacional a efectos del art. 5.1 CBr no debía ser "el lugar de cumplimiento de la obligación que servía de base a la demanda", sino el lugar correspondiente a la obligación característica del contrato, o lo que es lo mismo, el lugar donde debe ejecutarse la obligación del trabajador (locus laboris).

Dicho régimen especial de protección del trabajador de origen jurisprudencial, inspiró directamente la reforma del art. 5. 1 in fine del $\mathrm{CBr}$ en su versión dada por el Convenio de San Sebastián de 1989. Al mismo tiempo, se incorporó el art. 17. $5 \mathrm{CBr}$, siguiendo en cierta medida la solución contemplada en el Convenio de Lugano de 1988, que establecía la posibilidad de pactos atributivos de competencia judicial en materia de contratos individuales de trabajo. El Reglamento Bruselas I, que sustituyó al Convenio de Bruselas, supuso un cambio más de forma que de fondo en la regulación de la competencia judicial internacional en materia de contratos individuales de trabajo. En este sentido, y tal y como ya venía haciendo el Convenio de Roma sobre ley aplicable a obligaciones contractuales, se dedicó una sección especial para esta materia, integrada por un conjunto de normas destinadas a proteger a la parte más débil del contrato (Considerando 13 Reglamento Bruselas I). Vid. M. CASADO ABARQUERO, op. cit., pp. 134-139; P. MENÉNDEZ SEBASTIÁN, Competencia judicial internacional y ley aplicable al contrato de trabajo con elemento extranjero, Madrid, Lex Nova, 2006, pp. 73-75; R. M. MOURA RAMOS, "El contrato individual de trabajo", en A.-L. CALVo CARAVACA/L. Fernández de la GÁndara (Dirs.), Contratos internacionales, Madrid, Tecnos, 1997, pp. 1883-1905, esp. Pp. 1897-1898.
} 
la competencia judicial internacional en relación con los contratos de trabajo De tal forma que, una vez surgido el litigio, para determinar el tribunal competente solo se podrá acudir a los foros establecidos en esa sección?.

\section{A) Litigios laborales y sumisión de las partes}

19. El Reglamento Bruselas I admite la autonomía de la voluntad en cuanto a la elección del tribunal competente, si bien con ciertos límites establecidos para proteger a la parte débil en el contrato: el trabajador (art. 21 Reglamento Bruselas-I).

20. En este sentido, sólo se consideran válidos los pactos de sumisión expresa:

a) Cuando son posteriores al surgimiento del litigio. Con este límite a la autonomía de la voluntad en cuanto a la elección de tribunal competente se garantiza que el trabajador presta su consentimiento libremente. Una vez rota la relación jurídico-laboral, el empresario carece de poder coactivo sobre el trabajador. Surgido el litigio, éste último conoce el alcance real de los efectos derivados de la sumisión expresa a determinados tribunales.

b) Cuando son anteriores al nacimiento del litigio, siempre y cuando permitan al trabajador acudir a tribunales distintos de los previstos en los foros de carácter alternativo. Los acuerdos de sumisión expresa en materia de contrato de trabajo gozan, en este sentido, de naturaleza de foro pactado a favor de parte ${ }^{10}$.

21. En los contratos de trabajo celebrados entre Ryanair, o en su caso, Crewlink, y el personal de vuelo se incluye siempre un pacto de atribución de competencia a los tribunales irlandeses junto con una cláusula de elección del Derecho irlandés como ley rectora del contrato. Por lo que respecta a la cláusula atributiva de competencia, ésta carece de validez en tanto que no cumple con ninguno de los requisitos mencionados en el art. 21 Reglamento Bruselas-I (actual, art. 23 Reglamento Bruselas-I bis): a) dicha cláusula se inserta en el contrato con anterioridad al nacimiento del litigio; b) se invoca por parte del empresario y; c) finalmente, impide al trabajador ejercer su facultad de optar entre los tribunales legalmente previstos ${ }^{11}$.

\section{B) Trabajador demandante: locus labori}

22. En el marco del art. 19 Reglamento Bruselas I (actual art. 21 Reglamento Bruselas I-bis) objeto de la cuestión prejudicial planteada en la STJUE que aquí analizamos, los empresarios domiciliados en un Estado miembro pueden ser demandados, a elección del trabajador ante: a) los tribunales del Estado en que estuvieren domiciliados los empresarios (art. 19.1 Reglamento Bruselas-I), b) los tribunales de un Estado miembro distinto al Estado miembro del domicilio del empresario, que correspondan al lugar en el que el trabajador desempeñe habitualmente su trabajo o ante el tribunal del último lugar en que lo hubiere desempeñado (art. 19.2. a) Reglamento Bruselas-I); c) los tribunales del lugar en que estuviere o hubiere estado situado el establecimiento que hubiere empleado al trabajador, pero solo en el caso de que éste último no desempeñare o hubiere desempeñado habitualmente su trabajo en un único Estado (art. 19.2. b) Reglamento Bruselas-I).

23. El fundamento de estos foros, -foros en materia de contrato individual de trabajo-, es doble: de un lado, como foros especiales se justifican en el principio de proximidad, esto es, la estrecha relación existente entre el litigio y el tribunal correspondiente y de otro lado, como foros de protección tratan de centrarse en la necesidad de otorgar una adecuada atención a la parte débil e intentar restablecer el equilibrio en la relación contractual.

\footnotetext{
9 STJUE 14 septiembre de 2017, Asunto acumulados C-168/16 y C-169/16, /14, Crewlink y Ryanair, apartado 51.

10 Vid. M. CASADO ABARQUero, op. cit, pp. 152-153.

11 STJUE 14 septiembre 2017, Asuntos acumulados C-168/16 y C-169/16, Crewlink y Ryanair, apartados 52-54.
} 
24. En este contexto, el foro del "lugar donde el trabajador presta habitualmente sus servicios" (locus laboris) presenta diversas ventajas: a) favorece la coincidencia forum-ius, especialmente deseable en este materia en la que gran parte de las normas son normas de Derecho Público; b) proporciona protección jurídica al trabajador, parte débil del contrato, al facilitarle el acceso a los tribunales más cercanos con el consiguiente ahorro de costes; c) el establecimiento de un foro de competencia basado en criterios uniformes y objetivos simplifica el proceso de aplicación y proporciona seguridad jurídica en tanto que permite conocer, antes de que surja el litigio, los tribunales que pueden ser competentes para conocer del asunto ${ }^{12}$.

25. El principal inconveniente del locus laboris como criterio atributivo de competencia judicial internacional gira en torno a su determinación en relaciones laborales plurilocalizadas en las que tanto empleador como trabajador tienen domicilio en distintos Estados miembros, el trabajo se presta en distintos países, o incluso en zonas que no están sometidas a soberanía estatal. El TJUE ya ha tenido ocasión de fijar una posición jurisprudencial al respecto, si bien es cierto esta es la primera vez que se pronuncia en relación al personal de vuelo que presta sus servicios a bordo de aeronaves ${ }^{13}$.

\section{Lugar donde desempeña habitualmente su trabajo el personal de vuelo: el concepto de "base" como presunción}

26. La relación jurídico-laboral del personal de vuelo reviste una especial complejidad no sólo por su regulación, en la que confluye una diversidad de normas, sino por las circunstancias en las que se desarrolla. A diferencia de lo que sucede en las relaciones laborales típicas, en la actividad aérea no existe un lugar de trabajo fijo, estable y duradero A ello hay que sumar el actual contexto que atraviesa la aviación civil, dominado en gran parte por compañías low cost que han contribuido a crear un auténtico dumping social.

27. Con este telón de fondo, el TJUE trata de dar una solución a un difícil problema: determinar el lugar donde desempeña habitualmente su trabajo el personal de vuelo a efectos de fijar el tribunal competente, teniendo en cuenta que en estos casos, como el planteado en esta cuestión prejudicial, tanto los empresarios como los trabajadores tienen domicilios en Estados miembros distintos, que el trabajo del personal de vuelo se caracteriza por su movilidad, que la aeronave, aun teniendo la nacionalidad del Estado donde está matriculada, puede sobrevolar el espacio aéreo de diversos países a lo largo de una misma jornada laboral y que el personal de vuelo puede ser cedido a otras compañías aéreas, propietarias de otros aviones con distinta nacionalidad ${ }^{14}$.

\footnotetext{
12 Vid. M. CASADO ABARQUERO, op. cit, pp. 137-138.

13 Vid. STJCE 13 julio 1993, Asunto C-125/92, Mulox, (con comentarios de A. BORRÁs, "Nota", RJC, 1994, pp. 561-564; A. hUET, "Nota", JDI, 1994, pp. 539-546; p. LAGARde, "Nota", RCDIP, 1994, pp. 574-577; M. E. ZABalo escudero, "Nota", REDI, 1993, pp. 470-473. En el mismo sentido, STJCE 9 enero 1997, Asunto C-383/95, Rutten, con comentarios de H. GAUDEMETTALLON, "Nota", RCDIP, 1997, pp. 341-346); STJCE 27 febrero 2002, Asunto C-37/00, Weber, (con comentarios de J. L. IRIARTE ÁNGEL, "Trabajo en instalaciones situadas en la plataforma continental y competencia judicial internacional. Precisiones en torno a la STJCE de 27 de febrero de 2002", Diez años de Derecho Marítimo Donostiarra, Vitoria-Gasteiz, 2003, p. 89-101; P. MANKOWSKI, "Nota", IPRax, 2003, pp. 21-28.

${ }^{E n}$ sede de Derecho aplicable, vid.: STJUE 15 marzo 2011, Asunto C-29/10, Koelzch, (con comentarios de C. BRIÈRE,"Nota", JDI, 2012-1, pp. 190-196; F. JAULT-SESEKE, "Nota", RCDIP, 2011-1, pp. 455-461; J. MASEDA RODRíGUEZ, "Prestación laboral ejecutada en varios Estados y ley aplicable al contrato individual de trabajo", REDI, 2011-2, pp. 246-250; M. RODRÍGUEZ-PIÑEIRO Y BRAVO-FERRER, "Competencia judicial y ley aplicable en la Unión Europea al contrato de trabajo internacional”, Relaciones Laborales, 2011, núm. 10, versión on line; A. ZANOBETTI, "Employment contracts and the Rome Convention: the Koelzsch ruling of the european Corurt of justice", CDT, 2011-2, pp. 338-358); STJUE 15 diciembre 2011, Asunto C-384/10, Voogsgeerd, (con comentario de P. MAESTRE CASAS, "El contrato de trabajo de marinos a bordo de buques mercantes (A propósito de la STJE de 15 diciembre de 2011, Jan Voogsgeerd y Navimer SA, As. C-384/10), CDT, 2012-2, pp. 322-341).

14 Vid. P. COURSIER, Le conflit de lois en matière de contrat de travail. Étude en Droit International Privé français, Paris, JGDJ, 1993, pp. 97 y 108-109.
} 
El TJUE zanja la cuestión creando una presunción que conduce a equiparar el "lugar donde desempeña habitualmente su trabajo" el personal de vuelo con la "base". Para ello, el alto Tribunal, siguiendo la línea jurisprudencial ya existente en torno al art. 19. 2 Reglamento Bruselas I, basa su razonamiento en tres pilares: la interpretación autónoma del mencionado precepto, la interpretación amplia y el método analítico.

\section{Interpretación autónoma}

28. El TJUE comienza recordando que en los contratos individuales de trabajo, el foro previsto en el art. 19. 2 a) Reglamento Bruselas-I, que atribuye competencia a los tribunales del lugar donde el trabajador desempeña habitualmente sus servicios, está sujeto a una interpretación autónoma ${ }^{15}$. Y ello, en un doble sentido.

29. Por un lado, para fijar el "lugar donde el trabajador desempeña habitualmente el trabajo" no puede recurrirse al Derecho nacional de los Estados miembros sino que dicho concepto debe concretarse acudiendo a criterios uniformes proporcionados por el propio sistema. Sólo así se garantiza la aplicación uniforme de la normativa considerada, cuyo objetivo es unificar las reglas de competencia judicial internacional, evitando la multiplicidad de los criterios competenciales para una misma relación jurídica, y proporcionar al mismo tiempo seguridad jurídica facilitando al demandante y al demandado criterios de determinación del tribunal competente ${ }^{16}$.

30. Por otro lado, la interpretación autónoma del concepto del "lugar donde se desempeña habitualmente el trabajo" (art. 19.2. a) Reglamento Bruselas I) impide recurrir a criterios contenidos en otros instrumentos normativos tanto de Derecho internacional como de Derecho derivado europeo que no tengan por objeto la unificación de normas de Derecho Internacional Privado.

31. De ahí que el TJUE rechace cualquier equiparación jurídica de dicho concepto con el de "base" establecido en el anexo III del Reglamento (CEE) núm. 3922/917. Y también, descarte asimilar el "lugar donde se desempeña habitualmente el trabajo" con la "nacionalidad" de las aeronaves, en el sentido del art. 17 del Convenio de Chicago, de 7 de diciembre de 1944, sobre Aviación Civil Internacional ${ }^{18}$, algo que conduciría a considerar que el personal de vuelo desempeña habitualmente su trabajo en el territorio del Estado miembro cuya nacionalidad ostenta la aeronave propiedad de la compañía aérea correspondiente ${ }^{19}$.

Se trata con ello de evitar que un criterio atributivo de competencia judicial internacional, como en este caso "el lugar donde desempeña habitualmente su trabajo" el personal de vuelo, "se vea instrumentalizado o contribuya a la práctica de estrategias de elusión de obligaciones"20.

32. La interpretación autónoma del art. 19.2 Reglamento Bruselas I no impide por el contrario la toma en consideración las disposiciones correspondientes del Convenio de Roma, de 19 de junio de 1980, sobre ley aplicable a obligaciones contractuales, -actualmente, Reglamento (CE) núm. 595/2008, de 17 de junio, del Parlamento Europeo, sobre ley aplicable a obligaciones contractuales (en adelante,

${ }^{15}$ Ya en su momento, TJCE interpretó así el art. 5.1 CBr con el objetivo de proporcionar una protección de la parte débil de la relación jurídica, -el trabajador-, dando lugar a un concepto autónomo de lugar de cumplimiento de las obligaciones en relación al contrato de trabajo, que debía y debe determinarse acudiendo a criterios uniformes extraídos del propio sistema y de los objetivos perseguidos por el CBr (STJCE 26 mayo 1982, Asunto C-133/81, Ivanel; STJCE 15 enero 1987, Asunto C-266/85, Shevanai; STCE 15 febrero 1989, Asunto 32/88, Société Six Contructions).

16 STJUE 14 septiembre 2017, Asuntos acumulados C-168/16 y C-169/16, Crewlink y Ryanair, apartados 47 y 48.

${ }^{17}$ STJUE 14 septiembre 2017, Asuntos acumulados C-168/16 y C-169/16, Crewlink y Ryanair, apartados 65 y 66.

18 BOE núm. 311, 29 diciembre 1969. El Convenio de Chicago de 1944, en vigor en todos los Estados miembros de la UE, es el tratado normativo más importante en relación al Derecho Internacional Público Aeronáutico. Dicho Convenio tiene entre sus objetivos: reconocer la exclusiva soberanía de cada Estado en el espacio aéreo situado sobre su territorio, así como establecer unas mínimas reglas de funcionamiento de la aviación civil internacional, incluyendo aeronaves y aeropuertos, teniendo en cuenta el poder soberano de cada uno de los Estados.

19 STJUE 14 septiembre 2017, Asuntos acumulados C-168/16 y C-169/16, Crewlink y Ryanair, apartados 75 y 76.

20 STJUE 14 septiembre 2017, Asuntos acumulados C-168/16 y C-169/16, Crewlink y Ryanair, apartado 62. 
Reglamento Roma-I)-. Se trata con ello de preservar una interpretación armónica y coherente de los Reglamentos que regulan cuestiones de DIPr ${ }^{21}$.

En este sentido, conviene señalar que la alteración más importante del art. $6.2 \mathrm{CR}$ con respecto al actual art. 8.2 Reglamento Roma I, fue la introducción del criterio de la "base" o "base rule" como punto de conexión dominante para los contratos de trabajo del personal de vuelo ${ }^{22}$. Con ello se pretendía evitar para este tipo de contratos el recurso al siguiente punto de conexión previsto por la norma de conflicto -lugar donde se encuentre el establecimiento que haya contratado al trabajador-, algo que beneficiaba a todas luces al empresario ${ }^{23}$.

No obstante, el Reglamento de Bruselas I no debe interpretarse de forma idéntica a las normas del Reglamento Roma I, en tanto que estos Reglamentos persiguen objetivos propios. En ningún caso la congruencia pretendida puede llevar a interpretar las disposiciones del Reglamento Bruselas I de una manera ajena al sistema y a los objetivos de éste ${ }^{24}$. Sin embargo, y de forma sorprendente, el TJUE en los asuntos Crewlink y Ryanair hace gala de todo lo contrario como se verá más adelante.

\section{Interpretación amplia}

33. El principal problema que suscita el foro del lugar donde habitualmente se presta el trabajo, surge cuando empresario y trabajador tienen domicilios en Estados distintos y los servicios se desarrollan en más de un Estado. En tales casos, el TJUE ha declarado repetidamente que el criterio del Estado miembro en que el trabajador desempeñe habitualmente su trabajo debe interpretarse en sentido amplio $^{25}$. Así se entiende que el lugar de trabajo habitual es aquel desde el que el trabajador desempeña o cumple principalmente sus obligaciones respecto a su empresa, siendo un criterio orientador para concretar dicho lugar, la ubicación del despacho profesional desde el que el trabajador desempeña sus actividades, lugar en el que le trabajador ha establecido su residencia, y al que regresa después de cada uno de los desplazamientos ${ }^{26}$. A falta de un centro efectivo de actividades profesionales a partir del cual el trabajador cumpla sus obligaciones respecto a la empresa, y en ausencia de cualquier otro criterio, el lugar de trabajo desde el cual o partir del cual el trabajador desempeña sus obligaciones se refiere al lugar en el que el trabajador cumple de hecho lo esencial de sus obligaciones, esto es, el lugar donde el trabajador haya pasado la mayor parte de su tiempo ${ }^{27}$.

Por tanto y siguiendo una interpretación amplia del foro contenido en el art. 19.2 a) Reglamento Bruselas I, el hecho de que el trabajador desempeñe su trabajo en varios Estados no impide la aplicación del mismo, siempre y cuando la prestación de servicios en uno de esos Estados sea prevalente al resto según criterios cualitativos (importancia del trabajo), organizativos (centro de operaciones) o cuantitativos (número de horas) ${ }^{28}$.

34. En el supuesto de litigios que afectan a trabajadores empleados como miembros del personal de vuelo de una compañía aérea o puestos a su disposición, el "lugar en el que el trabajador desempañare habitualmente su trabajo" debe identificarse con el "lugar a partir del cual el trabajador cumple principalmente sus obligaciones respecto de su empresa" 29 .

\footnotetext{
${ }^{21}$ STJUE 14 septiembre 2017, Asuntos acumulados C-168/16 y C-169/16, Crewlink y Ryanair, apartados 55-56.

22 Propuesta de Reglamento del Parlamento Europeo y del Consejo sobre ley aplicable a las obligaciones contractuales (Roma I), Bruselas, 15 febrero 2005, COM (2005) 650 final, p. 7.

23 Vid. P. MANKOWSKI, "Employment Contracts under Article 8 of the Rome I Regulation", en F. FERRARI/s. LEIBLE (EDS.), Rome I Regulation. The Law Applicable to Contractual Obligations in Europe, Munich, 2009, pp170-216, esp. pp. 177-181, B. UBERTAZZI, Il Regolamento Roma I sulla legge applicabile alle obbligazione contrattuali, Milano, Giuffrè, 2008 , p. 94.

${ }^{24}$ STJUE 16 enero 2014, Asunto C-45/13, Kainz, apartado 20.

25 STJUE 14 septiembre 2017, Asuntos acumulados C-168/16 y C-169/16, Crewlink y Ryanair, apartado 57. No obstante conviene tener en cuenta que la interpretación amplia de este concepto seguida por el TJUE ha dejado vacío de contenido el foro previsto en el art. 19. 2. b) Reglamento Bruselas-I, algo que ha sido duramente criticado por cierto sector de la doctrina. Vid. M. CASADO ABARQUero, op. cit, pp. 146-148.

26 STJCE 13 julio 1993, Asunto C-125/92, Mulox; STJCE, de 9 de enero de 1997, Asunto C-383/95, Rutten.

27 STJCE 27 febrero 2002, Asunto C-37/00, Weber, apartado 49.

$28 \mathrm{Vid}$. A. TODOLí SIGNES, "La competencia judicial internacional del contrato individual de trabajo", Revista de Información Laboral, 2016-1, versión on line.

29 STJUE 14 septiembre 2017, Asuntos acumulados C-168/16 y C-169/16, Crewlink y Ryanair, apartado 60.
} 


\section{Método analítico: el concepto de "base" como presunción}

35. Para determinar dicho lugar, -"lugar a partir del cual el trabajador cumple principalmente sus obligaciones respecto de su empresa"-, el tribunal nacional debe basarse en una serie de indicios o elementos fácticos que le permitan tener en cuenta todas las circunstancias que caracterizan la actividad del trabajador ${ }^{30}$.

36. Varios son los indicios que, según el propio TJUE, pueden ser tenidos en cuenta por los tribunales nacionales, dada la especificidad de las relaciones laborales en el sector del transporte aéreo: a) el Estado miembro en el que está situado el lugar a partir del cual el trabajador desempeña sus misiones de transporte; b) aquél al que regresa una vez finalizadas sus misiones; c) el lugar donde recibe las instrucciones sobre sus misiones y organiza su trabajo; d) el lugar donde se encuentran las herramientas de trabajo; e) el lugar donde estén estacionados los aviones a cuyo bordo se desempeñe habitualmente el trabajo ${ }^{31}$.

37. Tal y como ha señalado el TJUE en la sentencia que comentamos, en el ámbito de los trabajadores empleados como personal de vuelo, hay un factor que está llamado a desempeñar un papel significativo en la identificación del "lugar a partir del cual el trabajador cumple sus obligaciones", y es precisamente, el concepto de "base", en el sentido del Reglamento (CE) núm. 3922/91.

Y ello, por varias razones: a) la "base" se define como "el lugar a partir del cual el personal de vuelo comienza sistemáticamente su jornada de trabajo y en el cual la termina, organizando en él su trabajo cotidiano, y cerca del cual los empleados, durante el período de cumplimiento de su contrato de trabajo, han establecido su residencia y están a disposición del transportista aéreo" (Reglamento (CE) núm. 3922/91, Anexo III, OPS 1.1095); b) los períodos de descanso mínimo del personal de vuelo difieren en función de si el tiempo de descanso se les atribuye fuera de la "base" o en la propia "base" (Reglamento (CE) núm. 3922/91, Anexo III, OPS 1.1110); c) finalmente, ese lugar no se determina aleatoriamente y tampoco lo elige el trabajador, sino que es el operador quien fija la "base" para cada miembro de la tripulación (Reglamento (CE) núm. 3922/91, Anexo III, OPS 1.1090, punto 3.1).

38. Por tanto, en los casos del personal de vuelo contratado por compañías aéreas o puesto a su disposición, el "lugar a partir del cual los trabajadores desempeñan habitualmente su trabajo" es aquél donde está situada la "base" asignada al trabajador, salvo que teniendo en cuenta los elementos fácticos de cada caso concreto existan "vínculos de conexión más estrechos" con otro lugar de trabajo distinto de esa "base" 32 .

39. El relevante papel otorgado a la "base" como criterio esencial para determinar el "lugar a partir del cual el personal de vuelo desempeña habitualmente su trabajo" ofrece importantes ventajas: a) otorga competencia judicial internacional a los tribunales del Estado más conectado con el litigio, cumpliendo con ello con el principio de proximidad; b) permite al trabajador acudir a los tribunales más cercanos a su domicilio, protegiendo a la parte más débil del contrato; c) ofrece previsibilidad y seguridad jurídica, permitiendo a las partes saber con anterioridad al surgimiento del litigio los tribunales competentes para conocer del mismo; d) coincide con el criterio establecido en esta materia por el art. 8.2 Reglamento Roma-I, alcanzándose así la deseada coherencia interna del sistema de DIPr dentro de la UE ${ }^{33}$.

30 STJUE 14 septiembre 2017, Asuntos acumulados C-168/16 y C-169/16, Crewlink y Ryanair, apartados 61 y 62.

31 STJUE 14 septiembre 2017, Asuntos acumulados C-168/16 y C-169/16, Crewlink y Ryanair, apartados 63 y 64.

32 STJUE 14 septiembre 2017, Asuntos acumulados C-168/16 y C-169/16, Crewlink y Ryanair, apartado 73.

33 Con el criterio de la "base" (base rule) como novedad con respecto al art. 6. 2 a) CR se pretendía evitar que ante una interpretación estricta del "lugar de trabajo habitual" se recurriese en tales casos al siguiente punto de conexión de la norma de conflicto - lugar donde esté situado el establecimiento a través del cual haya sido contratado el trabajador-, perjudicando con ello a la parte débil de la relación jurídica considerada. Fueron por tanto razones más de política legislativa que de dogmática jurídica, las que condujeron a la inclusión del criterio de la "base" en el art. 8.2 Reglamento Roma-I. De no haber sido así, y una vez descartada definitivamente como solución la lex libri o la lex registrationis, tales supuestos debían haber quedado subsumidos en el art. 6.2 b) CR, actual art. 8.3 Reglamento Roma-I. En cualquier caso, la solución finalmente retenida tiene la virtud de ofrecer seguridad y certeza jurídica. Vid. P. MANKOWSKI, “Employment Contracts...”, op. cit., pp. 178-180. 


\section{Algunas consideraciones críticas}

\section{Error de base}

40. En su afán por mantener una interpretación uniforme del art. 19.2 a) Reglamento Bruselas-I con el art. 6.2 CR, actual art. 8.2 Reglamento Roma-I, en pro a establecer cierta coherencia dentro del sistema de DIPr, el TJUE incurre en un error de base, que puede llevar aparejadas "peligrosas" consecuencias tanto en el ámbito de la competencia judicial internacional como en sede de derecho aplicable.

41. Según el TJUE, tal y como aparece reflejado en el apartado 73 de la Sentencia de 14 de septiembre de 2017: "la relevancia de la «base» para identificar el «lugar a partir del cual los trabajadores desempeñan habitualmente su trabajo» sólo desaparecería en el supuesto de que, habida cuenta de los elementos fácticos de cada caso, unas demandas como las examinadas en los asuntos principales presentasen unos vínculos de conexión más estrechos con un lugar de trabajo distinto a esa "base»".

Con esta afirmación, el TJUE confunde de forma sorprendente, el funcionamiento de las normas de competencia judicial internacional y las normas de conflicto, realizando una equiparación total entre el art. 19.2 a) Reglamento Bruselas-I y el art. 6.2 CR, actual art. 8.2-4 Reglamento Roma I.

\section{2. ¿Hacia una admisión del forum non conveniens en materia de contratos individuales de trabajo?}

42. El TJUE parece olvidar que el art. 19.2 Reglamento Bruselas-I, y de igual forma, el actual art. 21.1 Reglamento Bruselas-I bis, establece de forma objetiva dos foros únicamente: "lugar en que el trabajador desempeñe habitualmente su trabajo" y "lugar en el que estuviere situado el establecimiento que hubiere empleado al trabajador". Según el TJUE, es tal la relevancia de la "base", que por su sola presencia en este tipo de contratos de trabajo, sirve para identificar al primero de los foros mencionados, creando así a primera vista una presunción "legal". Si bien, y a renglón seguido, introduce la insólita posibilidad de recurrir a la "cláusula de excepción", mecanismo técnico jurídico reservado al ámbito conflictual, para desvirtuar dicha presunción cuando existan "vínculos de conexión más estrechos" con un lugar de trabajo distinto a la «base».

43. Con ello, la propia presunción establecida por el TJUE, convertida así en una presunción híbrida, -a caballo entre una presunción iure et de iure y una presunción iuris tantum-, abre la puerta en el ámbito de los contratos individuales de trabajo al forum non conveniens ${ }^{34}$. De tal suerte que si el tribunal que resulta competente en virtud del criterio de la "base", considera que existen vínculos más estrechos con otro lugar, podrá declinar su competencia ${ }^{35}$.

44. Y llama la atención, porque por todos es sabido que el Reglamento Bruselas-I se rige por el principio de predeterminación legal de la competencia. Ha sido el propio TJUE quien se ha encargado de establecerlo así en su propia jurisprudencia ${ }^{36}$. Resta por ver, si de aquí en adelante, la verdadera intención del Tribunal de Justicia en su Sentencia de 14 de septiembre de 2017, es establecer una excepción a dicho principio, o si, por el contrario, se ha tratado de un simple y mero error de consecuencias insospechables.

34 El forum non conveniens es un mecanismo del Derecho anglosajón que permite al juez rechazar el ejercicio de su competencia dada la escasa vinculación del asunto con el territorio de su país y la mayor vinculación con otro Estado. Vid. M. HERRANZ BALLESTEROs, El forum non conveniens y su adaptación al ámbito europeo, Valencia, Tirant lo Blanch, 2011; P. HERzOG, "La théorie du forum non conveniens en droit anglo-américain: un apperçu”, RCDIP, 1976, pp. 1-40; B. SCHNEIDER, "Le forum non conveniens et le forum conveniens (en dropit écossais, anglais et a méricain”, RIDC, 1975, pp. 602-642,

35 Vid. L. PAILER, loc. cit., p. 600.

36 Las normas de competencia judicial internacional establecidas en el Reglamento Bruselas I, actualmente Reglamento Bruselas I-bis, responden a los principios de previsibilidad y seguridad jurídica. De ahí que el propio TJUE haya indicado que la figura del forum non conveniens no puede aplicarse en el ámbito del mencionado Reglamento (STJCE 29 junio 1994, Custom; STJCE 1 marzo 2005, Owusu). 


\section{La "desnaturalización" de la "cláusula de excepción".}

45. De igual forma, y con el objetivo de garantizar la uniformidad en la interpretación de las normas de competencia judicial y de derecho aplicable existentes dentro de la UE, y teniendo en cuenta el absoluto paralelismo entablado en este caso concreto por el TJUE entre el art. 19.2 a) Reglamento Bruselas-I y el art. 6.2 CR, actual art. 8.2 a 4 Reglamento Roma-I, resulta legítimo cuestionarse en qué medida podrá influir este asunto, en la forma de concebir la "cláusula de excepción" en sede conflictual ${ }^{37}$.

46. La "cláusula de excepción" dejaría de tener por función la localización de la relación jurídica, en este caso el contrato individual de trabajo, con el lugar con el que presenta vínculos más estrechos, lugar distinto al designado por el punto de conexión principal, para pasar a desempeñar una función distinta destinada a encontrar o fijar el "lugar donde se presta habitualmente el trabajo". La "cláusula de excepción" pasaría a convertirse así en un expediente técnico jurídico accesorio, al servicio del punto de conexión predeterminado por la norma de conflicto, dejando atrás su verdadera función de corrección del mismo ${ }^{38}$.

\section{Desenlace}

47. La aplicación de la "doctrina" establecida por el TJUE en su Sentencia de 14 de septiembre de 2017, Asuntos Crewlink y Ryanair, no se ha hecho esperar, al menos, en España. Así, el Tribunal Superior de Justicia de la Comunidad Valenciana, en sentencia 9 enero 2018, rompiendo una línea jurisprudencial bien asentada desde hace tiempo en demandas similares, consistente en equiparar el lugar de la "base" al "lugar donde el trabajador presta habitualmente su trabajo" como criterio atributivo de competencia judicial internacional, y tras analizar los elementos facticos del caso, decide declararse incompetente ${ }^{39}$.

48. El TSJ y tras examinar las circunstancias que rodean el caso, tales como: lugar donde presta sus servicios el trabajador, lugar de celebración del contrato, idioma de redacción del mismo, existencia de una cláusula de elección de derecho aplicable y otra de elección de foro, lugar desde donde se emiten los cuadrantes de trabajo y se imparte el régimen disciplinario, la legislación aplicable en materia de Seguridad Social, lugar donde está situada la entidad bancaria a través de la cual se percibe el salario-, concluye que el "lugar donde el trabajador cumple sus obligaciones principales frente al empresario", no es España -lugar donde se sitúa la "base"-, sino una aeronave propiedad de Ryanair de nacionalidad irlandesa.

\footnotetext{
37 La cláusula de excepción es un mecanismo técnico-jurídico que sirve para corregir a la norma de conflicto en los casos en los que el Derecho designado por el punto de conexión no corresponde al país más vinculado con el supuesto. Vid. C. E. DUBLER, Les clauses d'exception en Droit internacional privé, Genève, Georg, 1983; K. IATRIDOU, Les clauses d'exception en matière de conflits de lois et des conflits de jurisdictions ou le príncipe de proximité, Dordrecht, Boston, M. Nijhoff Publishers, 1994.

${ }^{\mathrm{El}}$ art. 6.2 b) in fine $\mathrm{CR}$, actual art. 8.4 Reglamento Roma I prevé tal mecanismo. De tal forma que, si con independencia de cuál sea el país donde se presten de los servicios, el contrato de trabajo presenta vínculos más estrechos con otro país, se aplicará la ley de ese otro país. La aplicación de esta cláusula no es, sin embargo, "excepcional". El precepto no exige que la vinculación del caso con ese otro país sea "manifiesta" ni que tales vínculos con ese otro país se desprendan "claramente" de la situación. Basta acreditar con un análisis del conjunto de las circunstancias, que el contrato presenta vínculos más estrechos con un país distinto del indicado en los apartados a) y b) del art. 6. 2 CR (actuales, apartados 2 o 3 del art. 8 Reglamento Roma I). Desde este punto de vista, el art. 6. 2 in fine (actual art. 8. 4 Reglamento Roma I) opera como una auténticas "cláusula de escape" más que como una cláusula de excepción. Es el órgano jurisdiccional competente para decidir sobre el caso, el que deberá determinar si debe operar la cláusula de escape o no. Dicho órgano debe realizar un análisis razonado de la posible vinculación más estrecha del contrato con un Estado distinto del Estado de la realización habitual del trabajo. Vid. J. CARRASCOSA GONZÁLEZ, “Contratación laboral internacional", en A.-L. CALVO CARAVACA/J. CARRASCOSA GONZÁLEZ (DIRS.), Derecho Internacional Privado, vol. II, $17^{\mathrm{a}}$ ed., Comares, Granada, 2017, pp. 1289-1303, esp. pp. 1290-1292; o. Fotinopoulou BasurKo, La determinación de la ley aplicable al contrato de trabajo internacional, Cizur Menor, Thomson-Aranzadi, 2006, pp. 137-143; M. GARDEÑES SANTIAGO, "La regulación conflictual del contrato de trabajo en el Reglamento Roma I: Una oportunidad perdida", AEDIPr., t. VIII, 2008, pp. 387-424, esp. pp.415-418.

38 Vid. L. PAILER, loc. cit., p. 601.

39 TSJ C. Valenciana, (Sala de los Social, Sección 1ª), Sentencia núm. 33/2018 de 9 de enero, JUR\2018\115917.
} 


\section{Conclusiones}

49. Solo cabe esperar que en un futuro no muy lejano sea el propio TJUE quien determine la forma de desvirtuar la presunción establecida para los contratos de trabajo del personal de vuelo en el art. 19.2 a) Reglamento Bruselas-I, sin desnaturalizar con ello principios y mecanismos básicos y esenciales de Derecho Internacional Privado. Mientras tanto, serán de nuevo los tribunales de los social de los Estados miembros los que sigan lidiando con el problema de determinar el "lugar en el que el trabajador desempeña habitualmente su trabajo" en los casos del personal de vuelo.

50. Las consecuencias de la solución ofrecida por el TJUE en su Sentencia de 14 de septiembre de 2017, no podrían ser más decepcionantes: $1^{\circ}$ ) implica la admisión del foum non conveniens en materia de contrato individual de trabajo en el seno del art. 19. 2 a) Reglamento Bruselas-I (actual art. 21 Reglamento Bruselas-I bis), $2^{\mathrm{a}}$ ) se revierte la finalidad del método analítico utilizado por el propio TJUE para evitar que las partes en el contrato puedan instrumentalizar a su favor y a priori un determinado foro, consiguiéndose en este caso concreto el efecto contrario; $3^{\mathrm{a}}$ ) se vacía de contenido y de sentido el art. 19. 2 Reglamento Bruselas-I, en tanto que se priva al trabajador de poder elegir entre dos foros alternativos; $4^{\mathrm{a}}$ ) se desvirtúa el principio de proximidad; y $5^{\mathrm{a}}$ ) se termina resucitando el criterio del "registro" o "nacionalidad de la aeronave, criterio atributivo de competencia judicial internacional. 